\title{
Survey of alcohol-related presentations to Australasian emergency departments
}

\section{Diana Egerton- Warburton MBBS, FACEM Staff Specialist Director of Emergency Medicine Researchl, and Adjunct Clinical Associate Professor $^{2}$ \\ Andrew Gosbell Director $^{3}$ \\ Angela Wadsworth BA(Hons) Project Manager ${ }^{3}$ \\ Daniel M Fatovich MBBS, FACEM, PhD Professor of Emergency Medicine $^{4}$}

Drew B Richardson MBBS(Hons), FACEM, MD Chair of Road Trauma and Emergency Medicine

1 Monash Medical Centre Emergency Department, Monash Health Melbourne, VIC

2 School of Clinical Sciences, Monash University,

Melbourne, VIC.

3 Policy and Research Australasian College fo

Emergency Medicine

Melbourne, VIC

4 University of Western

Australia

Perth, WA

5 Emergency Department Australian National University Medical School, Canberra, ACT.

angela.wadsworth@ acem.org.au

MJA 2014; 201: 584-587 doi: $10.5694 / \mathrm{mjal} 4.00344$

\section{$\Delta$}

lcohol consumption in excess of that recommended in the National Health and Medical Research Council (NHMRC) alcohol guidelines ${ }^{1}$ is the norm in Australia. ${ }^{2}$ One in five Australians and New Zealanders drink at a level that increases their lifetime risk of alcohol-related disease or injury. 3,4 Almost half of Australians aged over 18 years $(44.7 \%)$ reported consuming an amount of alcohol on a single occasion in the preceding year that put them at an increased risk of acute injury. ${ }^{3}$

Emergency physicians are at the forefront of responding to and treating the consequences of alcohol-related harm. This ranges from treating alcohol intoxication and severe injuries sustained as a direct result of intoxication, to managing the acute complications of chronic alcohol-related conditions. While emergency departments (EDs) anecdotally see a high proportion of patients with alcohol-related injuries and conditions, there are very few national or state and territory prevalence data.

At present, it is not mandatory for Australian or New Zealand EDs to screen for or collect alcohol-related presentation data. Consequently, attempts to quantify alcohol-related presentations to EDs through existing datasets are likely to provide underestimates.

The literature to date has focused largely on alcohol screening and intervention strategies, and on patients with alcohol-related injuries presenting to EDs. Australasian studies have investigated the association between injuries and alcohol consumption in EDs and found that $17 \%-35 \%$ of total injury presentations to EDs involved alcohol consumption. ${ }^{5-8}$

Several small-scale prospective studies have attempted to quantify all alcohol-related presentations at a single site or local level.9,11 They

Abstract

Objective: To determine the proportion of alcohol-related presentations to emergency departments (EDs) in Australia and New Zealand, at a single time point on a weekend night shift.

Design, setting and participants: A point prevalence survey of ED patients either waiting to be seen or currently being seen conducted at 02:00 local time on 14 December 2013 in 106 EDs in Australia and New Zealand.

Main outcome measures: The number of ED presentations that were alcoholrelated, defined using World Health Organization ICD-10 codes.

Results: At the 106 hospitals (92 Australia, 14 New Zealand) that provided data, 395 (14.3\%; $95 \% \mathrm{Cl}, 13.0 \%-15.6 \%)$ of 2766 patients in EDs at the study time were presenting for alcohol-related reasons; $13.8 \%(95 \% \mathrm{Cl}, 12.5 \%-15.2 \%)$ in Australia and $17.9 \%(95 \% \mathrm{Cl}, 13.9 \%-22.8 \%)$ in New Zealand. The distribution was skewed left, with proportions ranging from 0 to $50 \%$ and a median of $12.5 \%$. Nine Australian hospitals and one New Zealand hospital reported that more than a third of their ED patients had alcohol-related presentations; the Northern Territory (38.1\%) and Western Australia (21.1\%) reported the highest proportions of alcohol-related presentations.

Conclusions: One in seven ED presentations in Australian and New Zealand at this 02:00 snapshot were alcohol-related, with some EDs seeing more than one in three alcohol-related presentations. This confirms that alcohol-related presentations to EDs are currently underreported and makes a strong case for public health initiatives.

found rates of alcohol-related harm ranging from $5 \%$ to $9 \%$ of all ED presentations. There have also been some site-specific studies of the impact of alcohol-related presentations on the ED workforce. ${ }^{12,13}$ Previous attempts to quantify harm on a regional level have been limited by having to rely on retrospective data and the use of diagnostic codes. These studies are likely to underestimate the true prevalence of alcohol-related presentations. For example, a Western Australian study found that alcoholrelated attendances to metropolitan EDs during 2002-2006 represented around $0.8 \%$ of all ED attendances. ${ }^{14}$

This study is the first large-scale, binational point prevalence study of alcohol harm in EDs to be carried out in Australia and New Zealand. The data will be used to establish the scale of alcohol-related presentations to EDs. It will provide a benchmark for further surveys, and enable informed community debate on this important public health issue.

\section{Methods}

We conducted a survey-based point prevalence study of EDs in Australia and New Zealand using a validated point prevalence "snapshot" method previously used to study access block. ${ }^{15}$ All EDs in Australia and New Zealand accredited by the Australasian College for Emergency Medicine (ACEM) for specialty training and non-accredited EDs that are part of the Emergency Medicine Education and Training (EMET) teaching network were included. Paediatric-only EDs were excluded from our analysis because alcohol-related presentations are rare among children. A survey instrument consisting of eight questions (Box 1) was developed and piloted by a reference group of emergency physicians and researchers.

Participating EDs were asked to nominate a site coordinator and provide a telephone number for the night of the survey. Each site coordinator was emailed the survey instrument 
and the list of definitions of alcoholrelated presentations (Box 2). Site coordinators were asked to educate all staff rostered on at the time of the survey.

The clinical definition of alcoholrelated presentations (Box 2) was developed by the reference group using a consensus approach. International statistical classification of diseases and related health problems, 10th revision (ICD-10) codes for alcohol intoxication were used. ${ }^{16}$ Broadly, the definition included presentations that were directly or indirectly related to alcohol consumption, as judged by the senior doctor in the ED at the time of the survey. Direct presentations were divided into injuries (intentional and unintentional), intoxication and medical conditions related to alcohol use. Indirect presentations were for intentional or unintentional injuries caused by a third party who was affected by alcohol. This definition was used as a guide for data collectors only. Individual types of alcohol harm were not recorded as this would have increased complexity and possibly reduced the response rate.

The survey was conducted at 02:00 local time, on Saturday 14 December 2013. The time and date was chosen by the researchers as being feasible for ED clinicians to complete the survey. The site coordinators received a reminder email the day before, and a short message service text message at 01:30 on the survey date. Data could be returned by fax, email or telephone. Where data were not returned by 02:10 local time, sites were contacted by telephone and further follow-up was undertaken in order to maximise response rates.

The Australian Capital Territory Health Department (ACT Health) Human Research and Ethics Committee's Low Risk SubCommittee approved this study, and site-specific governance approval was obtained. The primary outcome was the proportion of alcohol-related presentations in each ED at that point in time. For analysis, EDs were stratified by role delineation and by state and country. To maintain confidentiality and statistical meaning, we report aggregate data only. Data analysis was by descriptive statistics.

\section{The eight questions in the survey instrument}

1. Name of hospital?

2. Exact time data were collected?

3. Total number of patients waiting to be seen?

4. Number of patients with alcohol-related presentations* waiting to be seen?

5. Total number of patients currently being seen?

6. Number of patients with alcohol-related presentations* currently being seen?

7. If applicable, number of patients in the observation unit or short stay unit?

8. If applicable, number of patients with alcohol-related presentations* in the observation unit or short stay unit?

*Clinically intoxicated or presentation related to alcohol.

Comparisons were undertaken using $\chi^{2}$ and $t$ tests, as appropriate.

\section{Results}

All 126 ACEM-accredited hospitals in Australia and New Zealand were invited to participate. Seven of these (mostly paediatric and private hospitals) declined. A further nine nonaccredited hospitals also agreed to submit data. At the time of the survey, a further two hospitals declined, and 22 did not provide data, as shown in Box 3. The 106 responding hospitals identified 2766 patients in EDs at 02:00, of whom 395 (14.3\%; 95\% CI, $13.0 \%-15.6 \%$ ) had presented because of alcohol consumption. This is an average number of patients per ED of 3.8 in Australia and 4.0 in New Zealand (Box 4). The overall differences between Australia and New Zealand were only of borderline significance, with overlapping 95\% CIs $(P=0.05)$. Breakdown of rates by jurisdiction and role delineation are shown in Box 5.

The distribution of alcohol-related presentations among hospitals was skewed toward the left, with a range from zero (one New Zealand hospital, eight non-paediatric Australian hospitals) to 15 (one Australian hospital) and a median of two, with proportions ranging from 0 to $50 \%$ and a median of $12.5 \%$. In total, one New Zealand hospital and nine Australian hospitals (representing five states and territories) reported their prevalence of alcohol-related presentations to be more than a third of patients in the ED.

\section{Discussion}

In this study, we quantified the point prevalence of patients with alcoholrelated harm presenting to EDs on a binational scale. The study is

\section{Definition of alcohol-related presentations}

\section{Direct presentations}

1. Injuries

a. Unintentional injuries, including road traffic injuries, drowning, burns, poisoning and falls

b. Intentional injuries, which result from deliberate acts of violence against oneself or others

2. Intoxication

a. Alcohol involvement (blood alcohol concentration) as determined by breathalyser

b. Clinical intoxication: reasonable suspicion of any caring health professional (includes triage nurse if not yet seen by a doctor) that a patient is affected by recent alcohol consumption

c. Intoxication, but unrelated to clinical presentation

3. Medical condition as the result of the harmful use of alcohol

- G31.2 Degeneration of nervous system due to alcohol

- G62.1 Alcoholic polyneuropathy

- G72.2 Myopathy due to other toxic agents

- 142.6 Alcoholic cardiomyopathy

- K29.2 Alcoholic gastritis

- K70 Alcoholic liver disease

- F10.3 Alcohol withdrawal state

- F10.2 Alcohol dependence syndrome

- Other medical conditions that the treating physician believes are attributable to or exacerbated by alcohol (eg, Wernicke's encephalopathy, Korsakoff's dementia, cirrhosis, alcoholic hepatitis, hepatic encephalopathy, Barrett's oesophagus/ Mallory-Weiss syndrome/peptic ulcer/chronic diarrhoea, infection)

4. Mental health

a. Mental health presentations due to alcohol intoxication

b. Mental health presentations due to harmful use of alcohol

c. Overdose involving alcohol alone or as co-ingestant

5. Social problems

a. Z72.1 Problems of lifestyle: alcohol use

\section{Indirect presentations}

1. Injuries

a. Intentional or unintentional injuries caused by a third party affected by alcohol

representative of adult hospitals with an ED in Australia and New Zealand, having achieved an excellent geographic and role-related response rate. Our finding that one in seven patients in EDs in Australia and one in six in New Zealand present for reasons related to alcohol consumption indicates 
3 Participating hospitals and response rates by jurisdiction

\begin{tabular}{lccc} 
Jurisdiction & $\begin{array}{c}\text { Potential } \\
\text { hospitals }\end{array}$ & $\begin{array}{c}\text { Participating } \\
\text { hospitals }\end{array}$ & Response rate \\
\hline ACT & 2 & 2 & $100 \%$ \\
NSW & 40 & 30 & $75 \%$ \\
Vic & 27 & 21 & $78 \%$ \\
Tas & 4 & 4 & $100 \%$ \\
SA & 8 & 7 & $88 \%$ \\
Qld & 22 & 16 & $73 \%$ \\
NT & 2 & 2 & $100 \%$ \\
WA & 11 & 10 & $90 \%$ \\
All Australia & 116 & 92 & $79 \%$ \\
New Zealand & 19 & 14 & $74 \%$ \\
\hline
\end{tabular}

ACT = Australian Capital Territory. NSW = New South Wales. NT = Northern Territory. Qld = Queensland. SA = South Australia. Tas = Tasmania. Vic $=$ Victoria. $W A=$ Western Australia.

that previous research has underestimated the amount of alcohol-related harm presenting to Australasian EDs. It is notable that the prevalence was higher in Western Australia and much higher in the Northern Territory than in New South Wales and Victoria. Similarly, the much higher prevalence in major referral compared with urban district hospitals in Australia was expected, although it is of interest that this pattern was not repeated in New Zealand. Almost all EDs responding to this survey (91\% in Australia and 93\% in New Zealand) had at least one, and in some cases up to 15, alcoholrelated presentations at the time of the data collection. This shows that alcohol-related harms are widespread and not just confined to metropolitan "hot-spots".

In the absence of national datasets in Australia or New Zealand on alcohol-related presentations to EDs, our point prevalence study provides important evidence on the extent of the impact of alcohol misuse and the resultant impact on the acute health care sector.
Our study has several potential limitations. It represents a single point in time and, while providing an estimate of point prevalence, incidence cannot be estimated. The prevalence is likely to change over the time of day, day of the week and perhaps seasonally. We performed the survey in the pre-Christmas period, and this may have resulted in a higher proportion of alcohol-related presentations than might occur at other times of the year. Collecting more precise prevalence data would further clarify the extent of presentations of patients with alcohol-related harms to EDs, and inform preventive strategies and interventions. ${ }^{16}$ We therefore intend to undertake further research, including a 7-day prevalence study.

Non-responder bias may have resulted in EDs with differing rates of presentation of patients with alcohol-related harm not completing the survey. EDs with a low census of alcohol-related presentations may have been less motivated to respond compared with those with a high census. While our definition of "alcoholrelated" was based on ICD-10 codes, there is no internationally validated definition. This may have resulted in an underestimate of alcohol-related harm.

Measurement errors related to the definition of alcohol-related harm may have occurred. Ascertainment bias may have occurred with patients who appeared intoxicated being assumed to be intoxicated with alcohol, whereas their symptoms may instead have been caused primarily by other drugs. While our definition did include indirect alcohol-related harm, it is likely that the data collection method would underestimate the true prevalence of indirect harm.

\section{Prevalence of alcohol-related presentations at a single point in time in Australian and New Zealand} emergency departments (EDs), by status

\begin{tabular}{|c|c|c|c|c|}
\hline \multirow[b]{2}{*}{ Status } & \multicolumn{2}{|r|}{ Australia } & \multicolumn{2}{|r|}{ New Zealand } \\
\hline & Total & $\begin{array}{l}\text { No. alcohol-related } \\
(\% ; 95 \% \mathrm{Cl})\end{array}$ & Total & $\begin{array}{l}\text { No. alcohol-related } \\
(\% ; 95 \% \mathrm{Cl})\end{array}$ \\
\hline Waiting to be treated & 571 & 95 (16.6\%; 13.7\%-20.0\%) & 86 & 24 (27.9\%; 19.0\%-38.8\%) \\
\hline Being treated & 1425 & 194 (13.6\%; 11.9\%, 15.5\%) & 163 & 25 (15.3\%; 10.4\%-22.0\%) \\
\hline Being observed* & 458 & 50 (10.9\%; 8.3\%-14.2\%) & 63 & 7 (11.1\%; 5.0\%-22.2\%) \\
\hline Total number in all EDs & 2454 & 339 (13.8\%; 12.5\%-15.2\%) & 312 & 56 (17.9\%; 13.9\%-22.8\%) \\
\hline
\end{tabular}

* The number being observed is based on a smaller sample as three New Zealand hospitals and 28 Australian hospitals reported not having observation units.
Despite our use of site coordinators to train responding staff, the study design meant that most data were collected by busy clinical staff. Further standardisation of the measurement and recording of alcohol-related presentations that can be implemented in the context of busy EDs ${ }^{17}$ would assist, but would need to be resourced.

Our study happened to coincide with Operation Unite, ${ }^{18}$ a proactive binational policing initiative targeting alcohol-related antisocial behaviour in precincts across Australia and New Zealand, and heightening community awareness of the issue of excessive alcohol consumption. We acknowledge the potential confounding effects of this policing and public awareness campaign on our point prevalence data, but cannot determine their extent.

Not enough is yet known about the impact of alcohol-related presentations on ED resources. While we didn't specifically address this in our study, it is reasonable to extrapolate from our point prevalence data. Alcohol-related assaults on ED staff are common and appear to be increasing in frequency. ${ }^{12}$ Dealing with aggressive, intoxicated patients is resource-intensive and distressing for staff. It is likely that this will have a negative impact on the care of other patients in the ED, especially in a setting where one in three patient presentations are alcohol-related. This form of "innocent bystander" alcohol-related harm has not been quantified.

The contemporary discourse and policy response to alcohol misuse in the Australasian community emphasises law enforcement and regulatory initiatives. Our study draws attention to the important reality that alcohol misuse also has a significant impact on the health care system, as reflected in the very high prevalence of alcohol-related presentations in some EDs. As alcohol-related harm is an entirely preventable condition, and when hospitals in multiple jurisdictions report more than a third of their ED workload is due to this single cause, we contend that this represents a strong case for preventive public health interventions as a key component of a broad policy response to this issue. 
5 Prevalence of alcohol-related presentations as a proportion of all patients in Australian and New Zealand emergency departments

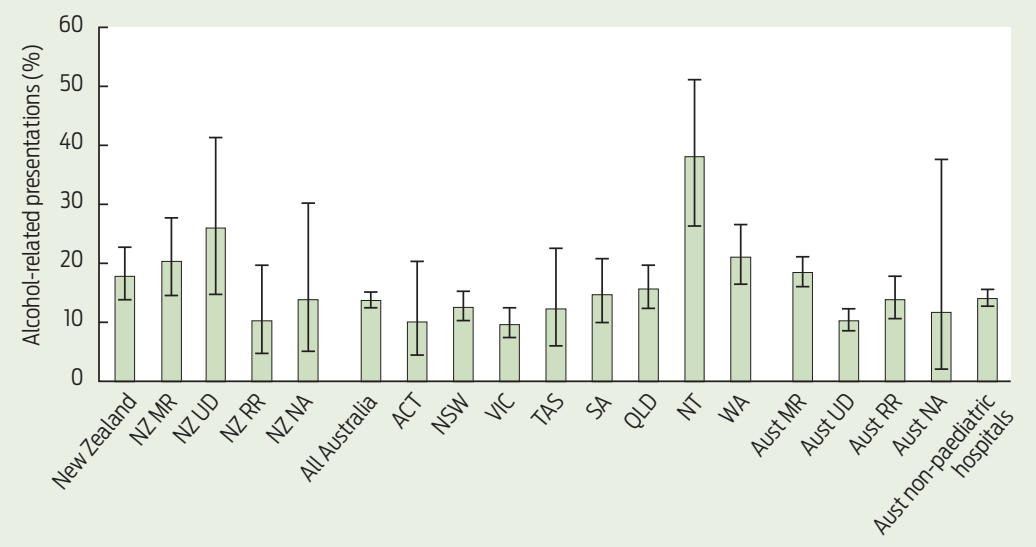

$\mathrm{MR}=$ major referral. $\mathrm{NA}=$ not accredited. $\mathrm{RR}=$ regional referral. $\mathrm{UD}=$ urban district

Abbreviations correspond to Australasian College for Emergency Medicine role delineation.

Evidence-based alcohol policies, along with effective strategies and interventions to reduce alcohol-related harm, are now more available than ever before. ${ }^{19}$ These should inform national solutions to the widespread alcohol misuse and harms afflicting local communities across Australia and New Zealand, along with addressing current societal attitudes towards excessive drinking.

Acknowledgements: We acknowledge principal funding from the Australian National Preventive Health Agency.

Competing interests: No relevant disclosures.

Received 12 Mar 2014, accepted 28 Jul 2014

1 National Health and Medical Research Council. Australian Guidelines to reduce health risks from drinking alcohol. Canberra: NHMRC, 2013. https://www.nhmrc.gov.au/_files_nhmrc/ publications/attachments/ds10-alcohol.pdf (accessed Oct 2014).
2 Foundation for Alcohol Research and Education. Annual alcohol poll: attitudes and behaviours. FARE, 2014. http://www.fare org.au/wp-content/uploads/2011/07/FAREAlcohol-Poll-2014_LR.pdf (accessed Apr 2014).

3 Australian Bureau of Statistics. Australian health survey: first results (2011-12) Canberra: ABS, 2012. (ABS Cat. No. 4364.0.55.001.) http:// www.ausstats.abs.gov.au/ausstats/subscriber. nsf/0/1680ECA402368CCFCA257AC90015AA4 E/\$File/4364.0.55.001.pdf (accessed Apr 2014).

4 Ministry of Health, New Zealand. Hazardous drinking in 2011/12: findings from the New Zealand health survey. Wellington: Ministry of Health, 2013. http://www.health.govt. $\mathrm{nz} /$ publication/hazardous-drinking-2011-12 findings-new-zealand-health-survey (accessed Apr 2014).

5 Humphrey G, Casswell S, Han DY. Alcohol and injury among attendees at a New Zealand emergency department. NZ Med J 2003; 116: U298.

6 Williams M, Mohsin, M, Weber D, et al. Alcohol consumption and injury risk: a case-crossove study in Sydney, Australia. Drug Alcohol Rev 2011; 30: 344-354.

7 Poynton S, Donnelly N, Weatherburn D, et al. The role of alcohol in injuries presenting to St
Vincent's Hospital Emergency Department and the associated short-term costs. Alcohol Studies Bulletin 2005; (6).

8 World Health Organization. Alcohol and injury in emergency departments: summary of the report from the WHO Collaborative Study on Alcohol and Injuries. Geneva: WHO, 2007. http://www.who.int/substance_abuse/ publications/alcohol_injury_summary.pdf (accessed Apr 2014).

9 Havard A, Shakeshaft AP, Conigrave KM. Prevalence and characteristics of patients with risky alcohol consumption presenting to emergency departments in rural Australia. Emerg Med Australas 2012; 24: 266-276.

10 Havard A, Shakeshaft AP, Conigrave KM, Sanson-Fisher RW. The prevalence and characteristics of alcohol-related presentations to emergency departments in rural Australia. Emerg Med J 2011; 28: 290-295.

11 Lesjak MS, McMahon GJ, Zanette L. Alcohol harm and cost at a community level: data from police and health. Rural Remote Health [internet] 2008; 8: 878.

12 Gilchrist H, Jones SC, Barrie, L. Experiences of emergency department staff: alcohol-related and other violence and aggression. Australas Emerg Nurs J 2011; 14: 9-16.

13 Gunasekara FI, Butler S, Cech T, et al. How do intoxicated patients impact staff in the emergency department? An exploratory study. NZ Med J 2011; 124: 1336.

14 Xiao J, Rowe R, Somerford P, et al. Impact of alcohol on the population of Western Australia. Perth: Epidemiology Branch, Department of Health WA, 2008.

15 Richardson D, Kelly AM, Kerr D. Prevalence of access block in Australia 2004-2008. Emerg Med Australas 2009; 21: 472-478.

16 World Health Organization. International statistical classification of diseases and related health problems, 10th revision. Geneva: WHO, 2010.

17 Waller S, Thom B, Harris S, Kelly M. Perceptions of alcohol-related attendances in accident and emergency departments in England: a national survey. Alcohol Alcohol 1998; 33: 354-361.

18 Australia New Zealand Policing Advisory Agency. Operation Unite. https://www.anzpaa. org.au/current-initiatives/operation-unite (accessed Feb 2014).

19 Alcohol and Public Policy Group. Alcohol: no ordinary commodity - a summary of the second edition. Addiction 2010; 105: 769-779. 